\title{
O IMPOSTO SOBRE A TRANSMISSÃO DE BENS IMÓVEIS E A SUA INCIDÊNCIA QUANDO DA AQUISIÇÃO DE TERRENOS PARA CONSTRUÇÃO FUTURA E IMÓVEIS NA PLANTA NO MUNICÍPIO DE BELO HORIZONTE
}

\author{
Filipe Lima Rios Carneiro ${ }^{1}$
}

Resumo: Este artigo abordará a estrutura do Imposto sobre a Transmissão de Bens Imóveis ITBI, passando pela Teoria Geral do Direito Tributário, notadamente pelos aspectos da Hipótese de Incidência, utilizando-se como marco teórico o livro Hipótese de Incidência Tributária de Geraldo Ataliba. Com base nessa abordagem será analisada a compatibilidade das cobranças de ITBI e ITBI complementar com multa e juros realizadas pelo Município de Belo Horizonte em casos de aquisição de terreno para realização de futura edificação e aquisição de unidades imobiliárias autônomas para entrega futura, com aqueles elementos da estrutura e Hipótese de Incidência do tributo.

Palavras-Chave: Imposto sobre a Transmissão de Bens Imóveis - Hipótese de Incidência Tributária - Aspecto Material - Aspecto Temporal - Tensão entre Fisco e Contribuintes

\author{
THE TAX ON THE TRANSMISSION OF IMMOVABLE PROPERTY AND ITS \\ IMPACT ON THE ACQUISITION OF LAND FOR FUTURE CONSTRUCTION AND \\ REAL ESTATE ON THE PLANT IN THE MUNICIPALITY OF BELO HORIZONTE
}

\begin{abstract}
This article will discuss the structure of the Tax on the Transmission of Real Estate - ITBI, passing through the General Theory of Tax Law, notably for the aspects of the Incidence Hypothesis, using as a theoretical framework the book Tax Injury Hypothesis of Geraldo Ataliba. Based on this approach will be analyzed the compatibility of ITBI and ITBI supplementary charges with fine and interest carried out by the Municipality of Belo Horizonte in cases of acquisition of land for future construction and acquisition of autonomous real estate units for future delivery, with those elements of tax incidence hypothesis.
\end{abstract}

Keywords:Tax on Real Estate Transmission - Tax Injury Hypothesis - Material Aspect - Temporary Aspect - Tension between Tax and Taxpayers

\footnotetext{
${ }^{1}$ Bacharel em Direito pela Faculdade de Direito Milton Campos (2012). Especialista em Direito Tributário pela Faculdade de Direito Milton Campos (2014). Mestrando em Direito das Relações Econômicas e Sociais pela Faculdade de Direito Milton Campos. Advogado. Sócio da Rabello \& Lima Sociedade de Advogados. Tem experiência na área de Direito, com ênfase em Direito Tributário. Membro efetivo da Comissão de Direito Tributário da OAB/MG, Triênio 2016 - 2018.

Lattes: http://lattes.cnpq.br/6726035222916894
} 


\section{INTRODUÇÃO}

O exercício da competência tributária deve ser praticado com razoabilidade ao passo em que, dado seu caráter expropriador, possui a capacidade de influenciar diretamente na conduta dos contribuintes.

Nesse sentido, ao influenciar as condutas de determinada população, o tributo acaba por influenciar diretamente os agentes de mercado e a economia de uma sociedade, o que muitas vezes acarreta em forte tensão entre o fisco e contribuintes.

Com a diversidade de tributos e competências tributárias que temos no Brasil, muitas vezes nos pegamos afastados da Teoria Geral do Direito Tributário, que sustenta todo o Sistema Tributário Nacional presente na Constituição Federal de 1988.

É justamente com este afastamento da Teria Geral do Direito Tributário, em um cenário em que a legislação tributária é infinita e complexa, que os equívocos e práticas de ilegalidades e inconstitucionalidades na cobrança de tributos ganham espaço e sustentabilidade.

No presente artigo será abordada a estrutura do Imposto sobre a Transmissão de bens Imóveis - ITBI e os elementos que compõem a sua Hipótese de Incidência, abordando os aspectos pessoal, espacial, material e temporal. Será utilizada como marco teórico a obra Hipótese de Incidência Tributária de Geraldo Ataliba.

Em seguida será feita a subsunção de duas situações específicas (aquisição de terreno para realização de futura edificação e aquisição de unidades imobiliárias autônomas para entrega futura) de cobrança do ITBI pelo Município de Belo Horizonte, com base na Lei n. ${ }^{\circ}$ Municipal n. ${ }^{0}$ 5.492/1988, aos aspectos da Hipótese de Incidência do tributo municipal, sempre com respaldo na obra de Geraldo Ataliba, para demonstrar o equívoco da cobrança do ITBI e seus consectários legais nestas situações específicas.

O tema abordado é de grande relevância, notadamente porque as cobranças de ITBI nas situações abordadas estão gerando problemas para os adquirentes de terrenos e imóveis na planta o que causa tensão entre os contribuintes e fisco municipal.

\section{APONTAMENTOS ACERCA DO IMPOSTO SOBRE TRANSMISSÃO DE BENS IMÓVEIS E OS AS ASPECTOS DA HIPÓTESE DE INCIDÊNCIA TRIBUTÁRIA}

Inicialmente cumpre dizer que o Imposto Sobre Transmissão de Bens Imóveis (ITBI) é 


\section{O IMPOSTO SOBRE A TRANSMISSÃO DE BENS IMÓVEIS E A SUA INCIDÊNCIA QUANDO DA AQUISIÇÃO DE TERRENOS PARA CONSTRUÇÃO FUTURA E IMÓVEIS NA PLANTA NO MUNICÍPIO DE BELO HORIZONTE}

um tributo que tem como fato gerador a transmissão, por ato oneroso, de bens imóveis, direitos reais sobre bens imóveis e direitos relativos à aquisição de bens imóveis. A sua base de cálculo é valor do imóvel ou direito relativo à bem imóvel a ser transmitido.

Nas palavras de Eduardo Sabbag:

É fato gerador do ITBI a transmissão inter vivos, a qualquer título, por ato oneroso (e não gratuito), de bens imóveis (e não móveis), por natureza ou acessão física, e de direitos reais sobre imóveis, exceto os de garantia, bem como cessão de direitos à sua

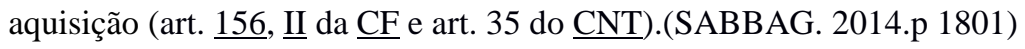

A despeito de o Código Tributário Nacional, editado em 1966, dispor que o tributo em questão é de competência dos Estados, com a promulgação da Constituição Federal de 1988, tal imposto passou a ser de competência dos Municípios, por força do artigo 156 inciso II. Nota-se:

Art. 156. Compete aos Municípios instituir impostos sobre:

I - propriedade predial e territorial urbana;

II - transmissão "inter vivos", a qualquer título, por ato oneroso, de bens imóveis, por natureza ou acessão física, e de direitos reais sobre imóveis, exceto os de garantia, bem como cessão de direitos a sua aquisição;

III - serviços de qualquer natureza, não compreendidos no art. 155, II, definidos em lei complementar. (Redação dada pela Emenda Constitucional n ${ }^{\circ}$ 3, de 1993)

IV - (Revogado pela Emenda Constitucional no 3, de 1993)

[...]( grifo nosso)

Acerca do tributo municipal, assim dispõe o Código Tributário Nacional:

Art. 35. O imposto, de competência dos Estados, sobre a transmissão de bens imóveis e de direitos a eles relativos tem como fato gerador:

I - a transmissão, a qualquer título, da propriedade ou do domínio útil de bens imóveis por natureza ou por acessão física, como definidos na lei civil;

II - a transmissão, a qualquer título, de direitos reais sobre imóveis, exceto os direitos reais de garantia;

III - a cessão de direitos relativos às transmissões referidas nos incisos I e II.

Parágrafo único. Nas transmissões causa mortis, ocorrem tantos fatos geradores distintos quantos sejam os herdeiros ou legatários.

[...]

Art. 38. A base de cálculo do imposto é o valor venal dos bens ou direitos transmitidos.(BRASIL, Lei 5172. 1966, arts. 35 e 38)

Para o correto desenvolvimento do presente artigo é indispensável à abetura de parentenses para uma visita à Teoria Geral do Direito Tributário, notadamente no que diz respeito à hipótese de incidência tributária. Isto porque, no presente artigo, será demonstrada a incompatibilidade do (i) ITBI incidente sobre terrenos adquiridos para construção futura e (ii) os encargos incidêntes sobre a cobrança de ITBI complementar quando da aquisição de imóveis 
na planta para entega futura pelo Município de Belo Horizonte, com alguns aspectos da hipótese de incidência tributária.

Como é cediço, a hipótese de incidência tributária é composta por quatro aspectos, quais sejam:
- $\quad$ Pessoal
- $\quad$ Espacial
- $\quad$ Material
- $\quad$ Temporal

O aspecto pessoal da hipótese de inciência é o elemento que determina os sujeitos da obrigação tributária. Nas palavras de Geraldo Ataliba:

O que, na lei, recebe a qualificação de aspecto pessoal da h.i. é a determinação explícita ou implícita - do sujeito ativo e o estabelecimento do critério para identificar o sujeito passivo, critério esse que também pode vir explícito (o que é mais raro) ou implícito. (ATALIBA, 2010, p. 81).

A sujeição ativa tributária é considerada a condição outorgada ao ente público para cobrar a exação, sempre com base na competência tributária que lhe outorgou poderes para instituir e cobrar o tributo.

No caso do ITBI, a pessoa política competente para instituí-lo e efetuar a sua cobrança, ou seja, o Sujeito Ativo, é o Município onde se encontra o imóvel objeto do fato gerador.

Já o Sujeito Passivo da obrigação tributária, no caso do ITBI, será qualquer uma das partes envolvidas na operação tributada, a ser estabelecido pelo Município, ou seja, o adquirente ou transmitente dos bens imóveis, ou direitos sobre bens imóveis; cedente ou cessionário na cessão de direitos sobre bens imóveis. Essa condição encontra previsão nos artigos 121 e 122 do Código Tributário Nacional. Vejamos:

\footnotetext{
Art. 121. Sujeito passivo da obrigação principal é a pessoa obrigada ao pagamento de tributo ou penalidade pecuniária.Parágrafo único. O sujeito passivo da obrigação principal diz-se:

I - contribuinte, quando tenha relação pessoal e direta com a situação que constitua o respectivo fato gerador;

II - responsável, quando, sem revestir a condição de contribuinte, sua obrigação decorra de disposição expressa de lei.
}

Art. 122. Sujeito passivo da obrigação acessória é a pessoa obrigada às prestações que constituam o seu objeto.(CTN.1966)

Já o aspecto espacial é o local eleito de forma expressa ou implícita pelo legislador como o local onde deverá ocorrer o fato que dará origem à obrigação tributária.

Novamente, nas palavras de Geraldo Ataliba, em seu livro Hipótese de Incidência 


\title{
O IMPOSTO SOBRE A TRANSMISSÃO DE BENS IMÓVEIS E A SUA INCIDÊNCIA QUANDO DA AQUISIÇÃO DE TERRENOS PARA CONSTRUÇÃO FUTURA E IMÓVEIS NA PLANTA NO MUNICÍPIO DE BELO HORIZONTE
}

Tributária, adotado como marco teórico, do presente artigo:

\begin{abstract}
Designa-se por aspecto espacial a indicação de circunstâncias de lugar, contidas explícita ou implícitamente na h.i., relevantes para a configuração do fato imponível. Os fatos imponíveis - como fatos concretos da vida real, inseridos no mundo fenomênico - acontecem num determinado lugar. A ubicação dos fatos imponíveis é essencial à configuração da obrigação tributária. (ATALIBA, 2010, p. 104).
\end{abstract}

No caso do ITBI, o aspecto espacial está atrelado ao local em que localizado o bem imóvel objeto da transação.

Para grande parte da doutrina o aspecto material é o mais importante da hipótese de incidência tributária, na medida em que nele está consubstanciado o fato sobre o qual desencadeará a tributação e, consequentemente, será objeto de tributação. Nas palavras de Geraldo Ataliba:

Aspecto material é a imagem abstrata de um fato jurídico: propriedade imobiliária, patrimônio, renda, produção, consumo de bens, prestação de serviços, ou uma atuação pública (como o estado realizar obra, produzir um serviço, conceder uma licença, uma autorização, uma dispensa, etc.)

$[\ldots]$

Fornece o critério básico, para se responder “quanto é devido", além de servir de fulcro para o discrímen que permite formular a única classificação jurídica dos tributos, desdobrando-os em espécies e subespécies. (ATALIBA, 2010, p. 107).

O aspecto temporal, por sua vez, diz respeito à designação do momento em que se considera consumado o fato gerador da obrigação tributária.

Junto com o aspecto material, o aspecto temporal é considerado por notável parte da doutrina como um dos aspectos mais importantes da hipótese de incidência tributária. No caso do presente artigo, estes dois são os aspectos mais relevantes para a abordagem pretendida.

Especificamente em relação ao aspecto temporal da hipótese de incidência tributária, assim ensina Geraldo Ataliba:

A lei continente da h.i. tributária traz a indicação das circunstâncias de tempo, importantes para o configuração dos fatos imponíveis. Esta indicação pode ser implícita ou explícita. Na maioria das vezes é simplesmente implícita.

$[\ldots]$

A mais importante função do aspecto temporal diz respeito à indicação necessariamente contida na hipótese de incidência - do momento em que se reputa ocorrido o fato imponível (e, pois, nascida a obrigação tributária).

$[\ldots]$ 
Define-se o aspecto temporal da h.i. como a propriedade que esta tem de designar (explícita ou implicitamente) o momento em que se deve reputa consumado (acontecido, realizado) um fato imponível. (ATALIBA, 2010, p. 94).

Os modos mediante os quais o legislador se expressa são os mais variados. Isto é relevante, para fins da exata apuração da lei aplicável (questões de vigência e eficácia da lei), da observância da irretroatividade (art. 150, III, “a”) e anterioridade (art. 150, III, “b”), além da contagem dos prazos de decadência e prescrição. (ATALIBA, 2010, pgs. 94/95).

Há um limite constitucional intransponível à discrição do legislador, na fixação do aspecto temporal: não pode ser anterior à consumação (completo acontecimento) do fato. Isto violaria o princípio da irretroatividade da lei (art. 150, III, “a”). Daí a inconstitucionalidade das antecipações dos tributos (algumas vezes camufladas sob a capa da substituição tributária). (ATALIBA, 2010, p. 95).

Na visão de Eurico de Santi, in versus:

O direito temporaliza o tempo quando o legislador determina prazos com os quais surgem e extinguem-se direitos e deveres. E o tempo como fato jurídico reflete-se, entre outras formas, nos eventos previstos nas hipóteses de incidência, com seu início, sua duração e seu termo final. (DE SANTI, 2000, p.38.)

Ainda nas palavras de Paulo de Barros Carvalho, entende-se como critério temporal da hipótese de incidência tributária o, in versus:

[...] grupo de indicações, contidas no suposto da regra, e que nos oferecem elementos para saber, em que preciso instante acontece o fato descrito, passando a existir um liame jurídico que amarra devedor e credor em função de um objeto - o pagamento de certa prestação pecuniária.(CARVALHO,2000,p 258-259)

No caso do ITBI, portanto, o aspecto temporal é momento em que se encontra transmitida a propriedade sobre bem imóvel ou a transmissão e/ou cessão de direitos reais sobre bens imóveis e direitos relativos à aquisição de bens imóveis.

Das referidas considerações dois aspectos que ganham destaque e são de observância obrigatória são (i) a materialidade da hipótese de incidência, ou seja, o fato que da origem à tributação deverá guardar relação com a base de cálculo sobre a qual incidirá a alíquota do tributo e (ii) um tributo não pode ser cobrado antes da consumação completa do fato eleito pelo legislador como aspecto material da hipótese de incidência, sob pena de violação ao Princípio da Irretroatividade da Lei Tributária, previsto no art. 150, inciso III, alínea “b” da Constituição 

QUANDO DA AQUISIÇÃO DE TERRENOS PARA CONSTRUÇÃO FUTURA E IMÓVEIS NA PLANTA NO MUNICÍPIO DE BELO HORIZONTE

Federal $^{2}$, salvo nos casos de substituição tributária, amparados pelo art. 150, §7 da Constituição Federal. Seguem artigos para melhor compreensão:

Art. 150. Sem prejuízo de outras garantias asseguradas ao contribuinte, é vedado à União, aos Estados, ao Distrito Federal e aos Municípios:

$[\ldots]$

III - cobrar tributos:

a) em relação a fatos geradores ocorridos antes do início da vigência da lei que os houver instituído ou aumentado;

b) no mesmo exercício financeiro em que haja sido publicada a lei que os instituiu ou aumentou;

$[\ldots]$

$\S 7^{\circ}$ A lei poderá atribuir a sujeito passivo de obrigação tributária a condição de responsável pelo pagamento de imposto ou contribuição, cujo fato gerador deva ocorrer posteriormente, assegurada a imediata e preferencial restituição da quantia paga, caso não se realize o fato gerador presumido. (Incluído pela Emenda Constitucional n ${ }^{\circ} 3$, de 1993) (BRASIL. 1988. art.150)

\section{DAS COBRANÇAS DO ITBI SOBRE TERRENOS E DOS ENCARGOS INCIDENTES SOBRE O ITBI COMPLEMENTAR INCIDENTE SOBRE UNIDADE AUTÔNOMA ADQUIRIDA PARA ENTREGA FUTURA REALIZADAS PELO MUNICÍPIO DE BELO HORIZONTE}

Frequentemente as partes envolvidas na aquisição de terrenos com a finalidade de construção de imóveis, sejam elas incorporadores visando a realização de incorporação imobiliária para comercialização de unidades autônomas futuras, sejam elas membros de um grupo de pessoas visando a contratação de empresa construtora para a realização da construção, ficam em dúvida acerca da base de cálculo a ser adotada para o cálculo do ITBI no Município de Belo Horizonte.

Isto porque, a legislação da capital mineira, especificamente o art. 16 da Lei n. ${ }^{\circ}$ 5.492/1988, estipula duas bases de cálculo para o ITBI, a serem aplicadas conforme o caso concreto. Confira-se:

Art. 16 - Na aquisição de imóvel pronto para entrega futura, em construção, a base de cálculo do imposto será o valor venal do imóvel como se pronto estivesse, apurado 
na forma prevista no art. $5^{\circ}$ desta Lei.

$\S 1^{\circ}$ - No caso de aquisição de terreno, ou sua fração ideal, de imóvel construído ou em construção, deverá o contribuinte comprovar que assumiu o ônus da construção, por conta própria ou de terceiros, mediante a apresentação dos seguintes documentos:

I- contrato particular de promessa de compra e venda do terreno ou de sua fração ideal, com firmas reconhecidas;

II- contrato de prestação de serviços de construção civil, celebrado entre o adquirente e o incorporador ou construtor, com firmas reconhecidas;

- documentos fiscais ou registros contábeis de compra de serviços e de materiais de construção;

III-quaisquer outros documentos que, a critério do fisco municipal, possam comprovar que o adquirente assumiu o ônus da construção.

$\S 2^{\circ}$ - Na hipótese do $\S 1^{\circ}$ deste artigo, a base de cálculo do imposto será o valor venal do terreno acrescido do valor venal da construção existente no momento em que o adquirente comprovar que assumiu o ônus da construção. (BRASIL,Lei 5.492, 1988, art. 16, grifo nosso).

Da leitura do supracitado art. 16 da Lei n. ${ }^{\circ}$ 5.942/1988 é possível concluir que:

a) O ITBI somente pode ter como base de cálculo o valor venal do terreno (acrescido de qualquer edificação existente na época da compra do imóvel) quando a obra for custeada pelos adquirentes do terreno, mesmo quando contratarem um terceiro para executar a obra ou, ainda, quando os adquirentes de um imóvel em construção assumirem o ônus da obra. Significa que a base de cálculo descrita neste item só é cabível se o adquirente assumir a responsabilidade de construir. Para o contribuinte fazer jus à esta base de cálculo, deve comprovar por meio de vários documentos seu enquadramento nessa hipótese. Exemplo: três amigos compram um terreno e constroem por conta própria um prédio com três apartamentos para morarem;

b) O ITBI tem como base de cálculo o valor venal do imóvel pronto (dividido pelas unidades um edifício, por exemplo) quando o consumidor adquirir um imóvel em construção de quem irá executar ou está executando a obra, seja por conta própria ou por terceiros, e, após a aquisição, a obra continuar sendo de responsabilidade de quem vendeu a unidade ao novo adquirente. Exemplo: João adquire um apartamento "na planta” de uma construtora (que é proprietária do terreno, que fez o projeto, que emprega sua mão de obra, que compra os materiais, etc.), através de pagamentos diluídos ao longo da obra, cuja entrega das chaves está prometida para dezembro de 2020 .

Por óbvio, economicamente é mais vantajoso para o contribuinte recolher o ITBI com base no valor do terreno adquirido para construção do imóvel (hipótese do item “a”). Contudo, segundo a legislação municipal, para que seja possível realizar o recolhimento do tributo se valendo desta base de cálculo, é necessário que o contribuinte se enquadre na hipótese descrita no $\S 1^{\circ}$, da Lei n. ${ }^{\circ} 5.492 / 1988$, e tenha condições de comprovar tal enquadramento. Ou seja, o contribuinte deverá comprovar que adquiriu o terreno e assumiu o ônus da construção do imóvel 
mediante a apresentação da seguinte documentação:

- Contrato particular de promessa de compra e venda do terreno ou de sua fração ideal, com firmas reconhecidas;

- Contrato de prestação de serviços de construção civil, celebrado entre o adquirente e o incorporador ou construtor, com firmas reconhecidas;

- Documentos fiscais ou registros contábeis de compra de serviços e de materiais de construção;

- Quaisquer outros documentos que, a critério do fisco municipal, possam comprovar que o adquirente assumiu o ônus da construção.

Ocorre que, o Município de Belo Horizonte, em duas situações específicas, vem cobrando o ITBI de modo flagrantemente incompatível com os aspecotos da hipótese de incidência tributária do tributo municipal, quais sejam:

- Uma pessoa física ou jurídica compra um terreno com ou sem construção existente (neste caso a construção é demolida) para posteriormente erguer uma edificação. O simples fato de existir um projeto arquitetônico em trâmite ou já aprovado na Prefeitura, tem feito com que o Fisco Municipal realize o lançamento do ITBI tendo como base de cálculo do valor da edificação futura pronta e acabada. Doravante deonominada “Primeira Situação”.

- Uma pessoa física ou jurídica compra uma unidade autônoma de um empreendimento imobiliário para entrega futura. O Fisco Municipal cobra o ITBI sobre o valor da fração ideal do terreno correspondente à unidade autônoma adquirida, mas, ao final da obra, cobra ITBI complementar com a incidência de multa e juros sobre a diferença entre o imposto calculado sobre o valor da unidade autônoma pronta e o valor cobrado inicialmente (em que a base de cálculo foi a fração ideal do terreno). Doravante deonominada “Segunda Situação”.

Conforme será explicitado no próximo tópico, a cobrança do ITBI e consectários legais da forma que vem sendo realizada pelo Município de Belo Horizonte nestes casos é incompatível com alguns aspectos da hipótese de incidência tributária do ITBI.

4. DA INCOMPATIBILIDADE DO ITBI COBRADO PELO MUNICÍPIO DE BELO HORIZONTE COM A HIPÓTESE DE INCIDÊNCIA TRIBUTÁRIA DO IMPOSTO MUNICIPAL 
Feitas estas considerações acerca da estrutura do ITBI, os elementos de sua hipótese de incidência e expostas as duas situações específicas de cobrança do imposto pelo Município de Belo Horizonte, passamos a fazer uma subsunção dessas duas situações com os aspectos da hipótese de incidência tributária do ITBI.

No que diz respeito ao aspecto pessoal da hipótese de incidência tributária do ITBI, as situações narradas podem ser consideradas compatíveis com tal elemento da hipótese de inciência.

Isto porque, tanto no caso em que o Município cobra o ITBI de um terreno sobre o valor total estimado de um futuro empreendimento, quanto no caso em que ele lança um ITBI complementar com multa e juros quando constatada a diferença de um valor entre a unidade autônoma adquirida para entrega futura e o valor da unidade pronta e acabada, o Sujeito Ativo e Sujeito Passivo são aquelas pessoas designadas na hipótese de incidência do Imposto.

Em âmbos os casos, o Sujeito Ativo é o Município de Belo Horizonte e o Sujeito Passivo o adquirente (no primeiro exemplo, o adquirente do lote e, no segundo exemplo, o adquirente da unidade autônoma). Logo, não há violação ao aspecto pessoal da hipótese de incidência tributária do ITBI.

As situações narradas também estão de acordo com o aspecto espacial da hipótese de incidência do ITBI, na medida em que os fatos geradores ocorrem no Município de Belo Horizonte e o tributo é cobrado e destinado a este Município.

Lado outro, as cobranças de ITBI nas duas situações em comento se mostram incompatíveis com os demais aspectos da hipótese de incidência do imposto. A primeira situação se mostra incompatível com o aspecto material e o aspecto temporal, enquanto a segunda situação se mostra incompatível com o aspecto temporal.

Na primeira situação, em que o Fisco Municipal realiza o lançamento do ITBI tendo como base de cálculo o valor da futura edificação pronta e acabada quando uma pessoa física ou jurídica compra um terreno para realizar um futuro empreendimento, o aspecto material da hipótese de incidência do ITBI é flagrantemente violado, na medida em que o que se transmite é o terreno adquirido, sendo somente o valor deste que se incorpora ao patrimônio do adquirente. Com efeito, nesta situação a materialidade do imposto é a transmissão de bem imóvel, que no caso é o terreno, de modo que somente este deve ser levado em consideração para a cobrança do imposto.

Já na segunda situação, em que o Fisco Municipal cobra o ITBI sobre o valor da fração 


\section{O IMPOSTO SOBRE A TRANSMISSÃO DE BENS IMÓVEIS E A SUA INCIDÊNCIA QUANDO DA AQUISIÇÃO DE TERRENOS PARA CONSTRUÇÃO FUTURA E IMÓVEIS NA PLANTA NO MUNICÍPIO DE BELO HORIZONTE}

ideal do terreno correspondente à unidade autônoma adquirida, mas, ao final da obra, cobra ITBI complementar com a incidência de multa e juros sobre a diferença entre o imposto calculado sobre o valor da unidade autônoma pronta e o valor cobrado inicialmente (em que a base de cálculo foi a fração ideal do terreno), o aspecto material da hipótese de incidência do imposto municipal não é violada. Isto porque, neste caso o fato gerador da obrigação tributária eleita pelo legislador é o direito à aquisição de determinado bem imóvel que, no caso, é uma unidade autônoma futura pronta e acabada.

Lado outro, quando tratamos do aspecto temporal da hipótese de incidência tributária do ITBI, ambas as situações se mostram incompatíveis.

Na primeira situação o Município é flagrado cobrando o ITBI sobre algo futuro e incerto, que não guarda relação com o aspecto temporal do tributo. No caso em comento, o aspecto temporal do ITBI é a transmissão do bem imóvel adquirido, que se considera consumada quando do registro do negócio jurídico no registro competente. Assim, o que é registrado é justamente a transmissão de um terreno e não de uma edificaçaõ futura pronta e acabada. Neste sentido, cumpre trazer citação do ilustre jurista Igor Mauler Santiago tratando da impossibilidade de se cobrar antecipadamente tributos de uma pessoa em razão de uma simples presunção do Fisco de que esta mesma pessoa irá praticar o fato gerador do tributo no futuro:

Usado a Constituição o termo responsável, claro está que se refere à pessoa chamada a pagar o tributo se ter realizado o respectivo fato gerador (embora esteja ele de algum modo vinculada, na forma do art. 128 do CTN). Noutras palavras: o art. 150, $\S 7^{\mathbf{0}}$ da Constituição não contém autorização para que os entes tributantes exijam antecipadamente de uma pessoa o tributo a nascer de fato gerador que se espera que ela mesma realize no futuro (antecipação do IPTU dos próximos cinco anos, cobrança em vida do imposto sobre heranças ou adiantamento de ICMS por venda a ser feita no futuro - hipótese em exame). E a discriminação não é desarrazoada: é sabido que a substituição tributária para a frente veio atender a um anseio de simplificação da fiscalização tributária, que fica concentrada em uns poucos contribuintes (os produtores ou atacadistas de certas mercadorias), ao invés de ter de dispersar-se por um sem-número de varejistas, pequenos e grandes, bem ou mal organizados, situados nos grandes centros ou em longínquos rincões. Ora, nenhuma utilidade teria para esse desiderato a antecipação do fato imponível próprio, já que a fiscalização de um mesmo contribuinte, agora ou mais tarde, acarreta sempre o mesmo ônus para o Fisco. (SANTIAGO, 2005, p. 47, grifo nosso).

Ainda em relação à violação do aspecto temporal da hipótese de incidência do ITBI, 
esta também se faz presente na segunda situação tratada no presente artigo. Isto porque, ao acrescer multa e juros ao ITBI complementar quando da entrega de uma unidade imobiliária autônoma pronta e acabada o fisco está considerando que no momento em que o contribuinte adquiriu o imóvel na planta já teria ocorrido o fato gerador do ITBI sobre a transmissão da unidade autônoma pronta e acabada.

Contudo, no momento da aquisição do imóvel pelo contribuinte, lhe foi transmitida a respectiva fração ideal do terreno correspondente a sua unidade, pelo simples motivo de que sequer havia unidade autônoma pronta a ser transferida na época. Inclusive, o próprio fato de a unidade autônoma ficar ou não pronta é um incógnita, eis que por diversos motivos tal unidade pode até mesmo nunca ser entregue.

Sendo assim, não pode o fisco cobrar multa e juros quando da cobraça do ITBI complementar neste caso, tendo em vista que na época da transmissão não havia unidade autônoma pronta e acabada sendo transferida, caracterizando a cobrança de multa e juros com base em fato gerador presumido, eis que este somente estará carcterizado no momento em que de fato for transferida a unidade autônoma pronta e acabada, ou seja, cabe ao fisco somente cobrar eventual ITBI complementar sem a incidência de multa e juros, tendo em vista que somente neste momento ocorreu o fato gerador do imposto em relação à transferência da unidade autônoma pronta e acabada.

Flagrante, portanto, à violação à Hipótese de Incidência Tributária do ITBI pelo Município de Belo Horizonte que realiza cobrança indevida do imposto e seus consectários legais (multa e juros) nas duas situações abordadas.

Tais cobranças vêm causando um aumento na tensão entre o fisco municipal e os contribuintes o que, via de consequência, acarreta em um maior número de discussões por meio de processos administrativos e judicias que poderiam não existir, caso o fisco controlasse sua sede arrecadatória e realizasse a cobrança do tributo dentro dos limites estabelecidos pela Teoria Geral do Direito Tributário, que sustentam todo o Sistema Tributário Nacional.

\section{TENSÃO ENTRE FISCO E CONTRIBUINTE}

Nota-se que no Brasil existe uma excessiva complexidade na regulamentação da legislação tributária, o que por vezes leva à interpretações equivocadas dessa legislação e, por consequencia, da hipótese de incidência de determinado tributo, o que pode acarretar em tributação indevida, onerando ainda mais os contribuintes. 


\section{O IMPOSTO SOBRE A TRANSMISSÃO DE BENS IMÓVEIS E A SUA INCIDÊNCIA QUANDO DA AQUISIÇÃO DE TERRENOS PARA CONSTRUÇÃO FUTURA E IMÓVEIS NA PLANTA NO MUNICÍPIO DE BELO HORIZONTE}

Conforme caso tratado no presente artigo, o contribuinte permanece como o elo mais frágil dessa relação para com o fisco, vez que necessita estar sempre em dia com suas obrigações fisicais, ainda que, em alguns casos, tenha que pagar tributos cobrados de forma indevida, em razão da utilização deturpada da competência tributária, sob pena de não conseguir desenvolver suas atividades e sobreviver.

Lado outro, conforme já abordado, aqueles contribuintes que não concordam com essa utilização deturpada da competência tributária pelo Fisco busca as vias administrativa e judicial para ter reconhecido o seu direito de recolher a exação no valor correto.

Como consequência da busca dos contribuintes pela cobrança tributária correta, os órgãos administrativos de julgamento e o poder judiciário ficam congestionados com diversas discussões envolvendo a cobrança de tributos que poderiam ser evitadas caso os fiscos exercecem suas respectivas competências tributárias pautadas nos ditames constitucionais e nas leis complementares, atrelados ainda à observância à finalidade de precípuo das receitas tributárias, que é prestar serviços públicos à população.

Entretanto, os fiscos históricamente não buscam pautar a arrecadação nas necessidades da população, mas sim em arrecar o máximo possível para manter a estrutura estatal que só cresce em detrimento da maior e melhor prestação de serviços públicos. Os pensamentos do professor Ives Gandra da Silva Martins traduzem essa ideia:

[...] a decisão que pertine ao nível da carga tributária é exclusivamente do governo, em quase todos os países, em todos os períodos históricos, [...] sem nenhuma participação popular; (MARTINS,2002, p. 72)

O Governo consome mais com as estruturas que com a efetiva prestação de serviços públicos (MARTINS,2002, p. 59)

É falsa a teoria de que a sociedade discute, através de seus representantes, a carga tributária ideal. [...] não se discute a necessidade do tributo para que o Estado possa prestar serviços públicos. O que se discute é o nível da carga tributária e a preferência histórica dos detentores do poder por fixá-la acima das necessidades estatais. [...].(MARTINS,2002, p. 75)

Com o poder de tributar exercído sem a participação dos contribuintes o que se tem visto é a pratica de abusos, notadamente quando estamos falando de legislações mais específicas, como aquelas relativas aos tributos estaduais e municipais. Trabalhando a idéia de que a discricionariedade/originalidade execessiva do legislador acaba por criar cobranças indevidas, veja o que diz Roque Antônio Carraza:

[...] o legislador de cada pessoa política (União, Estados, Municípios ou Distrito Federal), ao tributar, isto é, ao criar in abstracto tributos, vê-se a braços com o seguinte 
dilema: ou praticamente reproduz o que consta da Constituição - e, ao fazê-lo, apenas recria, num grau de concreção maior, o que nela já se encontra previsto - ou, na ânsia de ser original, acaba ultrapassando as barreiras que ela lhe levantou e resvala para o campo da inconstitucionalidade.(CARRAZZA, 2008 ,p 390.)

Patente, portanto, que relevante parte da legislação infraconstitucional ultrapassa os limites da competência tributária outorgada pela Constituição com a finalidade de arrecadar mais, em detrimento da incidência tributária correta e pautada na legalidade, eternamente buscada pelos contribuintes.

Tal prática deve ser coibida, sob pena de o governo prejudicar os contribuintes, que deveriam ser os destinatários dos serviços prestados pelo governo e não vítimas de cobranças abusivas e ilegais por parte dos fiscos.

O caso tratado no presente artigo retrata de forma clara o quanto os contribuintes do ramo da construção civil (um dos ramos de atividade que mais emprega no Brasil) podem ser prejudicados em razão da cobrança de tributo em desconformidades com os aspectos da hipótese de incidência tributária do Imposto sobre a Transmissão de bens Imóveis - ITBI.

Assim, além da forte retração que o setor da construção civil vem sofrendo nos últimos anos $^{3}$, ele ainda tem que enfrentar a cobrança de tributos em descompasso com os aspectos da hipótese de incidência do ITBI, onerando ainda mais a atividade e dificultando a retomada de seu crescimento.

\section{CONCLUSÃO}

Diante do exposto é possível concluir que a forma como o ITBI vem sendo cobrado pelo Município de Belo Horizonte (i) quando da aquisição de terrenos para construção futura,

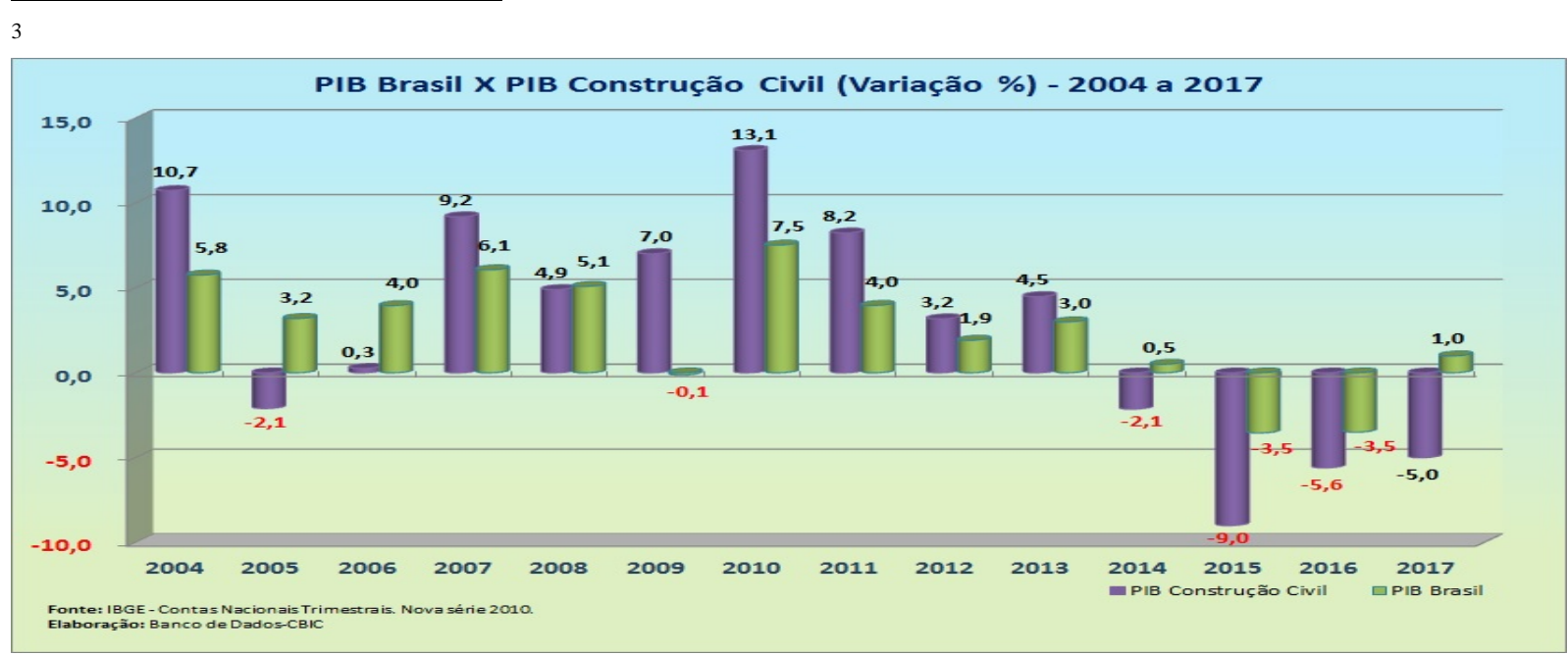




\section{O IMPOSTO SOBRE A TRANSMISSÃO DE BENS IMÓVEIS E A SUA INCIDÊNCIA QUANDO DA AQUISIÇÃO DE TERRENOS PARA CONSTRUÇÃO FUTURA E IMÓVEIS NA PLANTA NO MUNICÍPIO DE BELO HORIZONTE}

(ii) bem como os encargos incidêntes sobre a cobrança de ITBI complementar quando da aquisição de imóveis na planta para entega futura não guarda compatibilidade com os quatro aspectos da hipótese de incidência tributária do imposto municipal (pessoal, espacial, material e temporal).

Conforme demonstrado, enquanto na primeira situação a cobrança do imposto se mostra incompatível com os aspectos material e temporal da hipótese de incidência por tributar materialidade diversa daquela que é objeto da transação imobiliária e por antecipar fato gerador que supostamente será praticado no futuro, na segunda situação o aspecto temporal da hipótese de incidência não foi observado, tendo em vista que o Fisco antecipou o momento do fato gerador do ITBI quando da aquisição de uma unidade imobiliária autônoma a ser construída para o momento da aquisição desta, independentemente da condição deste imóvel, se pronto ou a ser construído.

Em que pese a compatibilidade das cobranças em comento com os aspectos pessoal e espacial da hipótese de incidência do ITBI, a incompatibilidade de daquelas com os aspectos material e temporal já são suficientes para invalidar as cobranças na forma que vem sendo realizadas, eis que a instituição e cobrança de impostos deve guardar total observância com os elementos norteadores da competência tributária, o que, inevitavelmente, passa pelo respeito às hipóteses de incidência tributária.

Por fim, com base na exposição realizada no presente artigo restou demonstrada a importância de se manter a cobrança dos tributos atrelada à Teoria Geral do Direito Tributário, sob pena de (i) serem chaceladas cobranças que distorcem os aspectos que compõem a hipótese de incidência tributária ou, quando menos, (ii) acarretar em maior tensão entre fisco e contribuintes, o que, consequentemente, leva à um aumento desnecessário do contencioso administrativo e judicial visando a anulação de cobanças tributárias indevidas.

\section{REFERÊNCIAS}

ATALIBA, Geraldo. Hipótese de Incidência Tributária. $6^{\circ}$ ed. $11^{\mathrm{a}}$ Tiragem. São Paulo, Malheiros Editores, 2010. 209 p. ISBN 85-7420-171-5.

BELO HORIZONTE. Prefeitura Municipal. Lei Municipal 5.492, de 28 de dezembro de 1988. Institui O Imposto Sobre Transmissão De Bens Imóveis Por Ato Oneroso "Inter Vivos". Disponível em: < https://leismunicipais.com.br/a/mg/b/belo-horizonte/lei-ordinaria/1988/549/5492/lei-ordinaria-n-5492-1988institui-o-imposto-sobre-transmissao-de-bens-imoveis-por-ato-oneroso-inter-vivos>. Acesso em: 20 mar. 2018. 
BRASIL. Constituição da República Federativa do Brasil, de 05 de outubro de 1988. Disponível em:<http://www.planalto.gov.br/ccivil_03/constituicao/constituicaocompilado.htm>. Acesso em: 20 mar. 2018.

BRASIL. Lei 5.172, de 25 de outubro de 1966. Dispõe sobre o Sistema Tributário Nacional e institui normas gerais de direito tributário aplicáveis à União, Estados e Municípios. Disponível em: <http://www.planalto.gov.br/ccivil_03/Leis/L5172.htm>. Acesso em: 20 mar. 2018.

CARRAZZA, Roque Antonio. Curso de direito constitucional tributário, 24. Ed. São Paulo, Malheiros, 2008. 1080 p.

CARVALHO. Paulo de Barros. Curso de Direito Tributário. $13^{\circ}$ edição. Ed. Ver. Atual. São Paulo: Saraiva, 2000.

DE SANTI, Eurico Marcos. Decadência e prescrição do direito tributário. São Paulo: Max Limonad, 2000.

MARTINS, Ives Gandra da Silva. Uma Teoria do Tributo. São Paulo: Quartier Latin, 2005.

SABBAG, Eduardo de Morais. Manual de direito tributário. 6ª Edição. São Paulo. Saraiva. 2014

SANTIAGO, Igor Mauler. A malversação do fato gerador e da base de cálculo do ICMS por alguns estados da federação (antecipação da cobrança por operação própria, com adoção de pauta fiscal e gross up): o exemplo das empresas de telefonia. Revista dialética de direito tributário, n. 113, p. 47-56, fev. 2005.

TCU. Confederação Nacional da Indústria. Relação entre o fisco e os contribuintes: propostas para reduzir a complexidade tributária. - Brasília : CNI, 2014. 27 p. : il. (Propostas da indústria eleições 2014 ; v. 26). 1. Revisão Tributária. 2. Fisco. I. Título. II. Série. CDU: 336.22. CNI. Confederação Nacional da Indústria. Disponível em: <http://webcache.googleusercontent.com/search?q=cache:p7VYm_64XCsJ:portal.tcu.gov. br/lumis/portal/file/fileDownload.jsp\%3FfileId\%3D8A8182A14939ECF401497AFBA5E378B 8+\&cd=4\&hl=pt-BR\&ct=clnk\&gl=br $>$. Acesso em: 20 mar. 2018. 